\title{
BMJ Open Using physician-linked mailed invitations in an organised colorectal cancer screening programme: effectiveness and factors associated with response
}

\author{
Jill Tinmouth, ${ }^{1,2,3,4}$ Nancy N Baxter, ${ }^{2,3,5}$ Lawrence F Paszat, ${ }^{2,6,7}$ \\ Linda Rabeneck, ${ }^{1,2,3,4,7}$ Rinku Sutradhar, ${ }^{2,7}$ Lingsong Yun ${ }^{2}$
}

To cite: Tinmouth J, Baxter NN, Paszat LF, et al. Using physician-linked mailed invitations in an organised colorectal cancer screening programme: effectiveness and factors associated with response. BMJ Open 2014;4:e004494. doi:10.1136/ bmjopen-2013-004494

- Prepublication history for this paper is available online. To view these files please visit the journal online (http://dx.doi.org/10.1136/ bmjopen-2013-004494)

Received 18 November 2013 Revised 4 February 2014 Accepted 10 February 2014

CrossMark

For numbered affiliations see end of article.

Correspondence to

Dr Jill Tinmouth;

jill.tinmouth@sunnybrook.ca

\section{ABSTRACT}

Objectives: A central tenet of organised cancer screening is that all persons in a target population are invited. The aims of this study were to identify participant and physician factors associated with response to mailed physician-linked invitations (study 1 ) and to evaluate their effectiveness in an organised colorectal cancer (CRC) screening programme (study 2).

Design and setting: 2 studies (study 1-cohort design and study 2-matched cohort design, comprising study 1 participants and a matched control group) were conducted in the context of Ontario's organised provincewide CRC screening programme.

Participants: 102 family physicians and 11302 associated eligible patients from a technical evaluation ('the Pilot') of large-scale mailed invitations for CRC screening were included. Matched controls were randomly selected using propensity scores from among eligible patients associated with family physicians in similar practice types as the Pilot physicians.

Intervention: Physician-linked mailed invitation to have CRC screening.

Outcomes: Uptake of faecal occult blood test (FOBT) within 6 months of mailed invitation (primary) and uptake of FOBT or colonoscopy within 6 months of mailed invitation (secondary).

Results: Factors significantly associated with uptake of FOBT included prior FOBT use, older participant age, greater participant comorbidity and having a female physician. In the matched analysis, Pilot participants were more likely to complete an FOBT (22\% vs $8 \%, p<0.0001)$ or an FOBT or colonoscopy ( $25 \%$ vs $11 \%, \mathrm{p}<0.0001)$ within 6 months of mailed invitation than matched controls. The number needed to invite to screen one additional person was 7 .

Conclusions: Centralised large-scale mailing of physician-linked invitations is feasible and effective in the context of organised CRC screening.

\section{INTRODUCTION}

Colorectal cancer (CRC) is the second leading cause of cancer-related deaths among men

\section{Strengths and limitations of this study}

- We describe the implementation of physicianlinked invitations in an organised colorectal screening programme that is characterised by a high level of primary care physician involvement and that operates in a context where opportunistic screening with colonoscopy is possible.

- We have shown that centralised large-scale mailing of physician-linked invitations is feasible and effective in this context.

- We found that physician-linked mailed invitations improve colorectal cancer screening participation by $14 \%$ such that seven physician-linked invitations need to be mailed to screen one additional person.

- We were limited to data found in Ontario health administrative databases; for example, we were not able to determine family history.

- Findings are promising but require appropriate infrastructure in order to be implemented in other jurisdictions.

and the third among women in Canada. ${ }^{1}$ Faecal occult blood testing (FOBT) ${ }^{2-4}$ and flexible sigmoidoscopy ${ }^{5-7}$ have been shown to decrease CRC mortality in randomised controlled trials.

Given these data, organised CRC screening programmes $^{8}$ are being implemented worldwide. $^{9}$ On 1 April 2008, Ontario launched ColonCancerCheck (CCC), Canada's first organised province-wide CRC screening programme. ${ }^{10}$ Through the primary care physician, FOBT is offered to people at average risk for CRC and colonoscopy to those at increased risk based on family history. The CCC programme uses a non-rehydrated guaiac FOBT (Hema-Screen, Immunostics, Inc, New Jersey, USA) requiring samples from three separate stools. While there are data to suggest that dietary restriction may be unnecessary, ${ }^{11}$ the programme recommends avoiding vitamin $\mathrm{C}$ 
for 3 days prior to and during the collection period in order to minimise false negative results.

Approximately $75 \%$ of Ontario residents received their care via a patient enrollment model (PEM) of care at the time of the study (2009). ${ }^{12}$ PEMs comprise teams of family physicians who provide their enrolled patients with comprehensive healthcare and extended hours. ${ }^{13}$ PEMs vary in terms of structure, services provided and remuneration (varying from enhanced fee-for-service to blended capitation). All Ontario physicians are remunerated for preventive care such as CRC screening; however, PEM physicians are incented to a greater degree than those who are not in PEMs. Specifically, PEM physicians receive a \$C7/patient fee for 'FOBT distribution and counseling', a \$C6.86/patient fee for 'CRC screening management' and an annual 'CRC screening preventive care bonus' (\$C220-\$C4000) depending on the proportion of enrolled patients who are up-to-date with FOBT (15$70 \%$ ). The physician is entitled to the CRC screening management fee if the enrolled patient attends an appointment to discuss CRC screening, has declined the test verbally or in writing or if there has been no response after two written notices and a telephone call from the physician. $^{14}$

A central tenet of organised screening programmes is that all persons in the target population be invited to participate. Implementation of this aspect of organised screening varies: invitations may be sent with an FOBT kit, can include physician recommendation or may incorporate tailored messaging. ${ }^{15}{ }^{16}$ Some of these approaches, such as incorporation of physician recommendation, present significant implementation challenges for organised screening programmes, such as those in Ontario.

In 2009, the CCC programme undertook the CCC Invitation Pilot (the Pilot), an evaluation that tested the technical feasibility of a centralised approach to sending physician-linked mailed invitations for CRC screening. In this paper, we describe the structure and the implementation of the Pilot. In addition, we report on participant and physician factors associated with response to mailed physician-linked invitations and on the effectiveness of these invitations in Ontario's organised CRC screening programme.

\section{METHODS}

The Pilot-implementation and evaluation

The CCC programme conducted the Pilot in November 2009. Invitation letters were generated by the CCC programme on behalf of 102 family physicians and sent to all their eligible enrolled patients. Just over 11000 eligible patient participants were sent mailed invitations requesting them to visit their family physician to obtain an FOBT kit or, if appropriate based on family history, a referral for colonoscopy. In this paper, we report on two studies using this cohort. Study 1 examines participant and physician factors associated with response to the mailed invitation among those who were sent the mailed invitation. Study 2 evaluates the effectiveness of the mailed invitation by comparing the uptake of CRC screening among study 1 participants to that of a matched control group. All analyses were conducted using SAS V.9 (SAS Institute, Cary, North Carolina, USA). A p value of 0.05 was used to determine statistical significance.

\section{Data sources}

The Pilot study was conducted at the Institute for Clinical Evaluative Sciences (ICES), which houses the administrative health records for all 13.5 million Ontarians. CCC programme databases were linked to the ICES administrative databases using an encrypted version of the provincial health insurance number.

The ICES databases used include the Canadian Institute of Health Information (CIHI) databases, the Ontario Health Insurance Program (OHIP) Claims History Database, the Registered Persons Database (RPDB), the Ontario Cancer Registry, the ICES Physician Database and the Client Agency Program Enrollment (CAPE) registry. The CIHI, OHIP, RPDB, the Ontario Cancer Registry and the ICES Physician Database are described elsewhere. ${ }^{17} 18$ The CAPE registry tracks patients enrolled to physicians who participate in PEMs and is a centralised electronic record of the linkage between specific patients and their physicians.

Since its inception, the CCC programme has collected data related to the FOBT kits administered by the CCC programme, including the results of these tests, using the Laboratory Reporting Tool (LRT).

\section{Study 1: factors associated with response to the mailed invitation \\ Cohort definition}

For the Pilot, a convenience sample of physicians participating in PEM-type practices was recruited via Cancer Care Ontario's Provincial Primary Care Cancer Network. Patients enrolled to these physicians, aged $50-74$ years without a history of CRC and who were due for CRC screening (without a health administrative data record of recent FOBT (previous 2 years) or lower gastrointestinal investigation including flexible sigmoidoscopy and colonoscopy (previous 5 years)), were eligible. For the Pilot mailing, CCC generated lists of patient participants eligible for CRC screening for each participating physician using CAPE, Ontario Cancer Registry, OHIP and LRT. All persons who were sent an invitation were included in the cohort, regardless of whether the letter was returned to the sender.

\section{The mailing}

Invitations were mailed in November 2009. The date of mailing was the index date. The letters were compiled centrally by the CCC programme but were physician linked; patient participants were sent a letter from their own physician, as indicated by their name at the bottom of the letter in an italicised font (figure 1). The letter asked participants to visit their family physician for 


\title{
ColonCancerCheck $\quad$ ContrôleCancer Colorectal $\left.\quad \mathcal{G}_{\text {cancer care }}^{\text {antario }}\right|_{\text {ontario }} ^{\text {actioncer }}$
}

From the office of Dr. George Black

Lawren Harris

June 1, 2009

456 Superior Street

Lindsay ON K2L 3M4

Dear Lawren Harris

You have received this letter because it is time to be screened for colon cancer. Our records as of April $1^{\text {st }}, 2009$ show that you have never had a fecal occult blood test (FOBT) or we do not know when you had your last FOBT. All adults between the ages of 50 and 74 years who are at average risk for colon cancer should do a FOBT every two years

If your parent, brother, sister or child has had colon cancer, your risk is higher and you should have a colonoscopy.

Please call my office to set up an appointment to talk about your risk for colon cancer and which test is right for you.

If you have recently completed colon cancer screening, please disregard this letter.

I look forward to hearing from you soon.

Dr. George Black

705-555-1212

\section{GET THE FACTS. GET CHECKED.}

- Colon cancer is the second most common cause of cancer death in Ontario

- Colon cancer can develop without any early warning signs.

- If it is caught early enough, 9 out of every 10 people can be cured.

- Regular screening is the best way to catch colon cancer early.

- The FOBT is a simple test that can be done at home

For more information please visit www.coloncancercheck.ca

\begin{abstract}
This letter has been sent on my behalf by ColonCancerCheck (CCC), Ontario's colorectal cancer screening program. CCC is a collaborative initiative of the Ministry of Health and Long-Term Care and Cancer Care Ontario. If for any reason you do not wish to receive future correspondence from the program, simply call the ColonCancerCheck Information Line at 1-866-662-9233 during business hours.
\end{abstract}

Figure 1 Mock-up of physician-linked invitation used in the Pilot.

screening; it did not include an FOBT kit. The letter was accompanied by a CRC screening information brochure and sent in an envelope with the family physician name in the front upper left corner. Pilot physicians were not compensated for study participation; however, they were able to apply the letter towards meeting the requirements for the CRC screening management fee (\$C6.86 per eligible enrolled patient).

\section{Response to mailed invitation}

We used a broad definition of response to the mailed invitation: any record of FOBT either in OHIP or in LRT within 6 months of the index date, regardless of the result (including rejected kits). Up to $10 \%$ of FOBT carried out in the province are captured only in OHIP, which does not have data on test results. We were not able to measure response in persons at increased risk of CRC as we do not have family history data available in the administrative databases.

\section{Participant and physician factors}

We characterised participants by age group, sex, comorbidity, median neighbourhood income,${ }^{19}{ }^{20}$ health region, ${ }^{21}$ immigration status and prior FOBT. We measured comorbidity by counting the number of Aggregated Diagnosis Groups (ADGs) using the Johns Hopkins ACG Case-Mix System in the prior 12 months. ${ }^{22}$ Mortality in a general population ambulatory cohort in Ontario was accurately predicted using this system. ${ }^{23}$ We used date of registration in the RPDB as a proxy measure for 
immigration status; participants were considered recent immigrants if their date of registration was within 5 years of the index date. ${ }^{24}$

Physicians were characterised according to age, sex, training location (Canada vs outside of Canada), practice type, size of practice, age-eligible rate of colonoscopy or FOBT over the past 2 years as well as the age-eligible rate of annual physical exams or influenza vaccinations in the prior year. All participating physicians were in PEMs; practice types included family health groups (FHGs, enhanced fee-for-service models), family health organisations or networks (FHO/FHNs, blended capitation models), $\mathrm{FHO} / \mathrm{FHN}$ with family health team (FHO/ FHN-FHT, interprofessional team model with a blended capitation fee structure) and other PEMs. ${ }^{25}$ We measured practice size as the number of enrolled patients stratified in a binary fashion ( $\leq 1800$ vs $>1800$ enrolled patients) as larger practice sizes have been shown to be associated with poorer preventative care. ${ }^{26}$ For the remaining physician characteristics, we identified all enrolled and non-enrolled patients aged 50-74 years in their practices as of the index date. Age-eligible FOBT and colonoscopy rates were obtained for each Pilot physician by calculating the proportion of their age-eligible patients who had had an FOBT or colonoscopy in the 2 years prior to the index date. Similarly, we calculated their rates of age-eligible annual physical examinations or influenza vaccine in the year prior to the index date. These variables were derived in order to estimate physician adherence to CRC screening and preventive medicine practices at baseline.

\section{Analysis}

The number and proportion of persons in the cohort who responded to the mailed invitation within 6 months were determined overall and by participant and physician characteristics. Multivariate logistic regression modelling was used to identify participant and physician factors associated with response to the mailed invitation. In order to account for potential clustering of participants within physicians, Generalized Estimating Equations $(\mathrm{GEE})^{27}$ were used in the model.

\section{Study 2: evaluation of the effectiveness of mailed}

\section{invitations}

Overview and study participants

This was a matched double cohort analysis, comparing the uptake of FOBT in those who were sent a mailed invitation (Pilot cohort) to that of a matched control group who were not sent a mailed invitation. The control group comprised patients who were enrolled to PEM physicians who had not participated in the Pilot. Control participants received 'usual care' from the CCC programme in terms of screening promotion. As such, they were eligible for screening via their primary care physician who was eligible for the same financial incentives as the Pilot physicians. Control participants were not sent a centralised physician-linked invitation from the CCC programme, although their physicians could send them a mailed invitation at their own discretion.

The Pilot cohort comprised all members of the cohort described in study 1 for whom a matched control could be identified. We identified potential controls as follows: (1) Pilot physicians were matched to non-Pilot physicians who were also practising in PEMs in a 1:5 ratio using physician age, sex, size and practice type; (2) individuals enrolled to the selected control physicians were retained if they met the same inclusion/exclusion criteria as those in the intervention cohort (aged 5074 years with no prior CRC who were due for CRC screening). As with the identification of eligible participants in the Pilot, we used CAPE, Ontario Cancer Registry, OHIP and LRT to determine eligibility of potential control participants.

Propensity scores that modelled the probability of belonging to the Pilot group were calculated for each participant in the entire group (Pilot and control). The variables in this model included age (as a continuous measure), sex, comorbidity, median neighbourhood income quintile, health region, immigration status and FOBT from 2 to 5 years previously. ${ }^{28} 29$ Pilot participants were matched to controls in a 1:1 fashion based on propensity scores using a calliper width of 0.25 . This methodology was implemented to balance the distribution of participant-level variables between the Pilot and control groups.

\section{Response to mailed invitation}

For our primary outcome, we defined response to the mailed invitation as in study 1 , a record of FOBT regardless of the result, within 6 months of the index date. For our secondary outcome, response was defined as a record of either FOBT or colonoscopy within 6 months of the index date. For the purposes of this study, controls were assigned the same index date as their matched counterpart in the Pilot group.

\section{Analysis}

Standard differences between the Pilot participants and controls were calculated for the variables included in the propensity score. Important differences between the two groups were defined by a standardised difference exceeding 0.1. ${ }^{29}{ }^{30}$ In the primary analysis, we compared the number and proportion in the Pilot and control groups responding to the mailed invitation with FOBT using McNemar's test. ${ }^{29}$ We determined the number of invitations mailed in order to screen one additional person with FOBT. We repeated the above analyses using our secondary outcome in order to determine if observed differences in FOBT uptake could be attributed to differences in colonoscopy uptake (ie, participants had CRC screening but chose colonoscopy over FOBT). As the matching only accounted for participant-level variables, we repeated our analyses using conditional logistic regression in order to adjust for physician covariates (age, sex, practice type and size). 


\section{Table 1 Patient participant and physician characteristics for study 1} $(n=2503)$

\section{Patient participants}

Age group in years, $\mathrm{n}(\%)$

50-59
$60-69$
$70-74$
Sex, n (\%)
Female
Male

Comorbidity*, number of ADGs (\%)

0

$1-2$

$3-4$

5-6

$7+$

Median neighbourhood income quintile, $\mathrm{n}(\%)$

Rural

Low urban

2

3

4

High urban

Health region, n (\%)

Erie St Clair

South West

Waterloo Wellington

Hamilton Niagara

Central West

Mississauga Halton

Toronto Central

Central

Central East

South East

Champlain

North Simcoe-Muskoka

North East

North West

Recent immigrant, n (\%)

FOBT 2-5 years prior to mailing, $n$ (\%)

\section{Physician}

Median age in years (IQR)

Sex, n (\%)

Female

Male

Training location, $\mathrm{n}(\%)$

Outside Canada

In Canada

Practice type, n (\%)

FHG

$\mathrm{FHO} / \mathrm{FHN}$

FHO/FHN-FHT

Other PEM

Practice size (enrolled patients), $\mathrm{n}(\%)$

$$
>1800 \text { patients }
$$

Age-eligible rate of colonoscopy quintile, $\mathrm{n}(\%)$

$\begin{array}{ll}\text { Low } & 485(19) \\ 2 & 548(22) \\ 3 & 637(25)\end{array}$

$1279(51)$
$894(36)$
$330(13)$
$1299(52)$
$1204(48)$

$257(10)$

828 (33)

$712(28)$

$393(16)$

313 (13)

394 (16)

360 (14)

402 (16)

429 (17)

432 (17)

486 (19)

125 (5)

284 (11)

76 (3)

289 (12)

138 (6)

22 (1)

111 (4)

24 (1)

361 (14)

162 (6)

219 (9)

77 (3)

291 (12)

324 (13)

23 (1)

643 (26)

52 (45-59)

936 (37)

1567 (63)

312 (12)

2191 (88)

1082 (43)

432 (17)

881 (35)

108 (4)

1105 (44)

485 (19)

637 (25)
No FOBT within 6 months

(n=8799)

Total

( $n=11302)$
$5384(61)$

2637 (30)

778 (9)

4554 (52)

4245 (48)

1279 (15)

3044 (35)

2241 (25)

1224 (14)

1011 (11)

$1431(16)$

$1375(16)$

1418 (16)

1430 (16)

1552 (18)

1593 (18)

337 (4)

823 (9)

251 (3)

976 (11)

482 (5)

120 (1)

392 (4)

177 (2)

1282 (15)

697 (8)

676 (8)

188 (2)

1118 (13)

1280 (15)

88 (1)

905 (10)

6663 (59)

3531 (31)

1108 (10)

5853 (52)

5449 (48)

1536 (14)

3872 (34)

2953 (26)

1617 (14)

1324 (12)

1825 (16)

1735 (15)

1820 (16)

1859 (16)

1984 (18)

2079 (18)

462 (4)

1107 (10)

327 (3)

1265 (11)

620 (5)

$142(1)$

503 (4)

201 (2)

1643 (15)

859 (8)

895 (8)

265 (2)

1409 (12)

1604 (14)

111 (1)

1548 (14)

53 (46-59)

52 (45-59)

3044 (35)

5755 (65)

3980 (35)

7322 (65)

1196 (14)

7603 (86)

1508 (13)

9794 (87)

4266 (48)

1456 (17)

2620 (30)

457 (5)

$5348(47)$

1888 (17)

3501 (31)

565 (5)

4104 (47)

5209 (46)

1619 (18)

2104 (19)

2488 (22)

1940 (22)

2279 (26) 
Table 1 Continued

\begin{tabular}{|c|c|c|c|}
\hline & $\begin{array}{l}\text { FOBT within } 6 \text { months } \\
(n=2503)\end{array}$ & $\begin{array}{l}\text { No FOBT within } 6 \text { months } \\
(\mathrm{n}=8799)\end{array}$ & $\begin{array}{l}\text { Total } \\
(n=11302)\end{array}$ \\
\hline 4 & $477(19)$ & $1696(19)$ & $2173(19)$ \\
\hline \multicolumn{4}{|c|}{ Age-eligible rate of FOBT quintile, $\mathrm{n}(\%)$} \\
\hline Low & $487(19)$ & $1888(21)$ & $2375(21)$ \\
\hline 2 & $504(20)$ & $1886(21)$ & $2390(21)$ \\
\hline High & $457(18)$ & $1455(17)$ & $1912(17)$ \\
\hline \multicolumn{4}{|c|}{ Age-eligible rate of annual physical examinations quintile, $\mathrm{n}(\%)$} \\
\hline Low & $496(20)$ & $2009(23)$ & $2505(22)$ \\
\hline 2 & $490(20)$ & $1625(18)$ & $2115(19)$ \\
\hline 3 & $472(19)$ & $1638(19)$ & $2110(19)$ \\
\hline 2 & 549 (22) & 1765 (20) & 2314 (20) \\
\hline 3 & 435 (17) & $1930(22)$ & 2365 (21) \\
\hline 4 & 485 (19) & $1770(20)$ & 2255 (20) \\
\hline High & 486 (19) & 1337 (15) & 1823 (16) \\
\hline
\end{tabular}

\section{RESULTS}

Study 1: factors associated with response to the mailed invitation

There were 11311 eligible patient participants associated with the 102 family physicians in the Pilot cohort. Nine participants were excluded, as we were unable to determine their health region and/or income quintile; this left 11302 participants for the analysis. The majority of participants were 50-59 years of age, $52 \%$ were women, $48 \%$ had no or low comorbidity and $14 \%$ had completed an FOBT from 2 to 5 years prior to the mailing. Two-thirds of participants had a male physician, approximately half were part of a primary care team reimbursed via an enhanced fee-for-service arrangement and just under half were enrolled in larger practices (>1800 enrolled patients; table 1).

In total, $2503(22 \%)$ completed an FOBT within 6 months of mailing. In the multivariate regression, the strongest participant factor associated with FOBT completion was prior FOBT use $(2-5$ years prior vs $>5$ years or never: OR 2.8, 95\% CI 2.5 to 3.3, p<0.0001). Other significant factors associated with FOBT completion included older participant age, greater comorbidity and having a female physician (table 2).

\section{Study 2: evaluation of the effectiveness of mailed} invitations

Of the 11302 participants in study 1, 10652 were successfully matched to 10652 controls using propensity scores. Standardised differences for the participant characteristics included in the propensity score were all
$<0.1$, indicating that the two cohorts were well matched for measurable potential confounders (table 3 ).

Pilot participants were significantly more likely than controls to complete FOBT alone (2387 (22\%) vs 854 $(8 \%), \mathrm{p}<0.0001)$ and FOBT or colonoscopy (2664 $(25 \%)$ vs $1191(11 \%), \mathrm{p}<0.0001)$ within 6 months of mailing. The association between the mailed invitation and CRC screening participation (either FOBT alone or FOBT or colonoscopy) remained after adjusting for physician level characteristics (table 4).

\section{DISCUSSION}

In the current study, we have demonstrated that physician-linked mailed invitations are feasible and effective in the context of a large organised, populationbased screening programme; only seven letters would need to be sent in order to screen one additional person. Furthermore, we have found that older participants, those with greater comorbidity, those who have previously been screened and those with female physicians, were more likely to respond to this type of invitation. Our findings are of particular interest to other jurisdictions planning or who already have organised CRC screening.

In other published studies of mailed invitations, an FOBT kit is often included with the invitation. Three studies carried out outside organised screening programmes have found physician-linked invitations to be superior to non-linked invitations; two of these studies included an FOBT kit, ${ }^{31}{ }^{32}$ and the third study did 
Table 2 Multivariate logistic regression analysis using Generalized Estimating Equations for the characteristics of participants and physicians associated with completing an FOBT within 6 months of the mailing date

\begin{tabular}{|c|c|c|}
\hline & OR $(95 \% \mathrm{Cl})$ & p Value \\
\hline \multicolumn{3}{|l|}{ Participants } \\
\hline \multicolumn{3}{|l|}{ Age group, years } \\
\hline $50-59$ & $0.6(0.5$ to 0.8$)$ & $<0.0001$ \\
\hline $60-69$ & $0.8(0.7$ to 1.0$)$ & NS \\
\hline 70-74 & Reference & NA \\
\hline \multicolumn{3}{|l|}{ Sex } \\
\hline Female & $0.9(0.9$ to 1.0$)$ & NS \\
\hline Male & Reference & NA \\
\hline \multicolumn{3}{|c|}{ Comorbidity ${ }^{\star}$, Number of ADGs } \\
\hline 0 & $0.7(0.6$ to 0.8$)$ & 0.0002 \\
\hline $1-2$ & $0.9(0.7$ to 1.0$)$ & NS \\
\hline $3-4$ & 1.0 (0.9 to 1.2$)$ & NS \\
\hline $5-6$ & 1.0 (0.9 to 1.2$)$ & NS \\
\hline $7+$ & Reference & NA \\
\hline \multicolumn{3}{|c|}{ Median neighbourhood income quintile } \\
\hline Rural & $0.9(0.7$ to 1.1$)$ & NS \\
\hline Low urban & 0.9 (0.7 to 1.0$)$ & NS \\
\hline 2 & $1.0(0.8$ to 1.1$)$ & NS \\
\hline 3 & $1.0(0.9$ to 1.1$)$ & NS \\
\hline 4 & 0.9 (0.8 to 1.1$)$ & NS \\
\hline High urban & Reference & NA \\
\hline \multicolumn{3}{|l|}{ Health region } \\
\hline Erie St Clair & 1.3 (0.9 to 1.8$)$ & NS \\
\hline South West & 0.9 (0.6 to 1.4$)$ & NS \\
\hline Waterloo Wellington & 0.8 (0.6 to 1.2$)$ & NS \\
\hline Hamilton Niagara & 0.9 (0.6 to 1.2$)$ & NS \\
\hline Central West & $1.0(0.7$ to 1.4$)$ & NS \\
\hline Mississauga Halton & 0.6 (0.3 to 1.2$)$ & NS \\
\hline Toronto Central & 0.8 (0.6 to 1.2$)$ & NS \\
\hline Central & 0.5 (0.4 to 0.7$)$ & 0.0004 \\
\hline South East & 0.8 (0.5 to 1.3$)$ & NS \\
\hline Champlain & $1.0(0.7$ to 1.4$)$ & NS \\
\hline North Simcoe-Muskoka & 0.9 (0.6 to 1.4$)$ & NS \\
\hline North East & $1.1(0.7$ to 1.5$)$ & NS \\
\hline North West & 0.7 (0.5 to 1.0$)$ & 0.03 \\
\hline Central East & Reference & NA \\
\hline \multicolumn{3}{|l|}{ Recency of immigration } \\
\hline Remote or non-immigrant & $1.0(0.6$ to 1.6$)$ & NS \\
\hline Recent immigrant & Reference & NA \\
\hline \multicolumn{3}{|l|}{ Prior FOBT use } \\
\hline $2-5$ years prior to mailing & 2.8 (2.5 to 3.3$)$ & $<0.0001$ \\
\hline$>5$ years or never & Reference & \\
\hline \multicolumn{3}{|l|}{ Physician } \\
\hline Increasing age (per year) & $1.0(1.0$ to 1.0$)$ & NS \\
\hline \multicolumn{3}{|l|}{ Sex } \\
\hline Female & $1.3(1.0$ to 1.5$)$ & 0.02 \\
\hline Male & Reference & NA \\
\hline \multicolumn{3}{|l|}{ Training location } \\
\hline In Canada & $0.9(0.7$ to 1.2$)$ & NS \\
\hline Outside Canada & Reference & NA \\
\hline \multicolumn{3}{|l|}{ Practice type } \\
\hline FHG & $0.9(0.7$ to 1.1$)$ & NS \\
\hline $\mathrm{FHO} / \mathrm{FHN}$ & $0.8(0.6$ to 1.1$)$ & NS \\
\hline Other PEM & 0.7 (0.4 to 1.0$)$ & 0.05 \\
\hline FHO/FHN-FHT & Reference & NA \\
\hline
\end{tabular}

Table 2 Continued

\begin{tabular}{|c|c|c|}
\hline & OR $(95 \% \mathrm{Cl})$ & p Value \\
\hline \multicolumn{3}{|c|}{ Practice size (enrolled patients) } \\
\hline$\leq 1800$ patients & $1.1(0.9$ to 1.3$)$ & NS \\
\hline >1800 patients & Reference & NA \\
\hline \multicolumn{3}{|c|}{ Age-eligible rate of colonoscopy quintile } \\
\hline Low & $1.1(0.8$ to 1.5$)$ & NS \\
\hline 2 & $1.2(1.0$ to 1.6$)$ & NS \\
\hline 3 & 1.0 (0.8 to 1.2$)$ & NS \\
\hline 4 & 1.0 (0.8 to 1.3$)$ & NS \\
\hline High & Reference & NA \\
\hline \multicolumn{3}{|c|}{ Age-eligible rate of FOBT quintile } \\
\hline 2 & $0.9(0.6$ to 1.3$)$ & NS \\
\hline 3 & 0.9 (0.7 to 1.2$)$ & NS \\
\hline 4 & $1.1(0.8$ to 1.4$)$ & NS \\
\hline High & 0.9 (0.7 to 1.3$)$ & NS \\
\hline Low & Reference & NA \\
\hline \multicolumn{3}{|c|}{ Age-eligible rate of annual physical examinations quintile } \\
\hline 2 & $1.4(0.9$ to 2.0$)$ & NS \\
\hline 3 & $1.3(0.9$ to 1.8$)$ & NS \\
\hline 4 & $1.3(0.9$ to 1.8$)$ & NS \\
\hline High & $1.1(0.8$ to 1.5$)$ & NS \\
\hline Low & Reference & NA \\
\hline \multicolumn{3}{|c|}{ Age-eligible rate of influenza vaccine quintile } \\
\hline 2 & $1.0(0.8$ to 1.2$)$ & NS \\
\hline 3 & $0.8(0.6$ to 1.0$)$ & 0.02 \\
\hline 4 & 0.9 (0.7 to 1.2$)$ & NS \\
\hline High & $1.3(1.0$ to 1.7$)$ & NS \\
\hline Low & Reference & NA \\
\hline \multicolumn{3}{|c|}{$\begin{array}{l}\text { *Comorbidity scored using number of ADGs using the Johns } \\
\text { Hopkins Case Mix System. } \\
\text { ADGs, Aggregated Diagnosis Groups; FHG, family health group; } \\
\text { FHO/FHN, family health organisations or networks; FHT, family } \\
\text { health team; FOBT, faecal Occult blood test; NA, not applicable; } \\
\text { NS, not significant; Other PEM, other patient enrolled model of } \\
\text { care. }\end{array}$} \\
\hline
\end{tabular}

not. ${ }^{33}$ Other studies have examined mailed invitations with FOBT kits in the context of primary care practices in the USA. ${ }^{34-36}$ While the results from these trials were largely supportive of mailed invitations, kit inclusion can make it difficult to separate the convenience of receiving the FOBT kit directly by mail from the impact of an invitation from one's own physician.

Our study demonstrates the effectiveness and feasibility of physician-linked invitations in the context of a large organised CRC screening programme with an estimated target population of over three million persons. Implementation in this context confers challenges in terms of technological infrastructure, privacy and regulatory issues. There are two studies (from the $\mathrm{UK}^{37}$ and Italy $^{38}$ ) that have reported on mailed invitations in the context of organised CRC screening programmes and found them to be effective. Both studies included FOBT kits and one studied the impact of physician endorsement specifically. ${ }^{37}$ Our findings are important because they support a potentially more cost-effective approach that avoids wasting kits that are mailed but not used. 
Table 3 Characteristics of the two cohorts matched by propensity score in study 2

\begin{tabular}{|c|c|c|c|}
\hline & $\begin{array}{l}\text { Pilot participants } \\
(n=10652)\end{array}$ & $\begin{array}{l}\text { Control participants } \\
(n=10.652)\end{array}$ & $\begin{array}{l}\text { Standardised } \\
\text { difference }^{*}\end{array}$ \\
\hline \multicolumn{4}{|l|}{ Participants } \\
\hline $50-59$ & $6248(59)$ & $6324(59)$ & 0.01 \\
\hline $60-69$ & $3342(31)$ & $3316(31)$ & 0.01 \\
\hline 70-74 & $1062(10)$ & $1012(10)$ & 0.02 \\
\hline Male & $5104(48)$ & $5175(49)$ & 0.01 \\
\hline \multicolumn{4}{|l|}{ Comorbidity†, number of ADGs (\%) } \\
\hline 0 & $1462(14)$ & $1425(13)$ & 0.01 \\
\hline $1-2$ & 3647 (34) & $3716(35)$ & 0.01 \\
\hline $3-4$ & $2764(26)$ & $2835(27)$ & 0.02 \\
\hline Low urban & $1628(15)$ & $1699(16)$ & 0.02 \\
\hline 2 & $1698(16)$ & $1728(16)$ & 0.01 \\
\hline 3 & $1728(16)$ & $1681(16)$ & 0.01 \\
\hline 4 & $1831(17)$ & $1753(16)$ & 0.02 \\
\hline High urban & $1942(18)$ & $1902(18)$ & 0.01 \\
\hline \multicolumn{4}{|l|}{ Health region, $\mathrm{n}(\%)$} \\
\hline Erie St Clair & $462(4)$ & $423(4)$ & 0.02 \\
\hline South West & $1107(10)$ & $1114(10)$ & 0 \\
\hline Waterloo Wellington & $327(3)$ & $343(3)$ & 0.01 \\
\hline Hamilton Niagara & $1265(12)$ & $1290(12)$ & 0.01 \\
\hline Central West & $620(6)$ & $580(5)$ & 0.02 \\
\hline North West & $954(9)$ & $954(9)$ & 0 \\
\hline Recent immigrant, n (\%) & $111(1)$ & $105(1)$ & 0.01 \\
\hline FOBT $2-5$ years prior to mailing, $n(\%)$ & $1476(14)$ & $1240(12)$ & 0.07 \\
\hline \multicolumn{4}{|l|}{ Physician } \\
\hline Median age in years (IQR) & $52(45-59)$ & $52(47-58)$ & NA \\
\hline \multicolumn{4}{|l|}{ Sex, $n(\%)$} \\
\hline Female & $3875(36)$ & 3335 (31) & NA \\
\hline Male & $6777(64)$ & $7317(69)$ & \\
\hline \multicolumn{4}{|l|}{ Practice type, n (\%) } \\
\hline $\mathrm{FHG}$ & $4854(46)$ & $4885(46)$ & NA \\
\hline $\mathrm{FHO} / \mathrm{FHN}$ & $1859(17)$ & $1718(16)$ & \\
\hline $\mathrm{FHO} / \mathrm{FHN}-\mathrm{FHT}$ & 3374 (32) & $3027(28)$ & \\
\hline Other PEM & $565(5)$ & $1022(10)$ & \\
\hline \multicolumn{4}{|l|}{ Practice size (enrolled patients), n (\%) } \\
\hline$>1800$ patients & $5366(50)$ & $5026(47)$ & NA \\
\hline
\end{tabular}

Our results highlight the critical role of physician recommendation, a finding supported by others. For example, in the National Health Service (NHS) Bowel
Cancer Screening Programme (BCSP) currently, the primary care physician receives the result but is not directly involved in the mailed invitation or the actual 
Table 4 Association between mailed invitation and FOBT completion or mailed invitation and FOBT or colonoscopy completion after adjusting for physician factors

\begin{tabular}{|c|c|c|c|c|}
\hline & \multicolumn{2}{|c|}{ FOBT completion } & \multicolumn{2}{|c|}{$\begin{array}{l}\text { FOBT or colonoscopy } \\
\text { completion }\end{array}$} \\
\hline & $\overline{\text { OR (95\% CI) }}$ & p Value & $\overline{\text { OR (95\% Cl) }}$ & p Value \\
\hline \multicolumn{5}{|l|}{ Mailed invitation } \\
\hline Yes (Pilot) & 3.3 (3.1 to 3.6$)$ & $<0.0001$ & 2.7 (2.5 to 2.9$)$ & $<0.0001$ \\
\hline No (controls) & Reference & NA & Reference & NA \\
\hline Increasing age (per year) & $1.0(1.0$ to 1.0$)$ & NS & $1.0(1.0$ to 1.0$)$ & 0.03 \\
\hline \multicolumn{5}{|l|}{ Sex, $N(\%)$} \\
\hline Female & $1.0(0.9$ to 1.1$)$ & NS & $1.0(0.9$ to 1.1$)$ & NS \\
\hline Male & Reference & NA & Reference & NA \\
\hline \multicolumn{5}{|l|}{ Practice type, N (\%) } \\
\hline FHG & $0.7(0.6$ to 0.8$)$ & $<0.0001$ & 0.7 (0.7 to 0.8$)$ & $<0.0001$ \\
\hline $\mathrm{FHO} / \mathrm{FHN}$ & $0.8(0.7$ to 0.9$)$ & $<0.0001$ & 0.8 (0.7 to 0.9$)$ & $<0.0001$ \\
\hline Other PEM & $0.8(0.7$ to 1.0$)$ & 0.03 & $0.8(0.7$ to 1.0$)$ & NS \\
\hline FHO/FHN-FHT & Reference & NA & Reference & NA \\
\hline \multicolumn{5}{|l|}{ Practice size (enrolled patients) } \\
\hline$\leq 1800$ patients & $1.2(1.1$ to 1.3$)$ & 0.0004 & $1.2(1.1$ to 1.3$)$ & $<0.0001$ \\
\hline$>1800$ patients & Reference & NA & Reference & NA \\
\hline
\end{tabular}

FHG, family health group; FHO/FHN, family health organisations or networks; FHT, family health team; FOBT, faecal occult blood test;

NA, not applicable; NS, not significant; Other PEM, other patient enrolled model of care.

screening. Recently, a randomised controlled trial conducted in the context of the BCSP showed that an endorsement letter from the primary care provider increased participation by $6 \% .^{38}$ In two studies from Australia, endorsement improved initial participation ${ }^{31} 32$ and over four successive screening rounds. ${ }^{32}$

Uptake of FOBT in Ontario is lower than that of some organised CRC screening programmes in other countries. For example, $30 \%$ of Ontarians were up-to-date with FOBT in 2008-2009 ${ }^{39}$ compared to $52 \%$ participation in the UK programme by October $2008,{ }^{40} 54 \%$ in the Italian programme in $2007^{41}$ and $54 \%$ in the New Zealand pilot programme in 2012. ${ }^{42}$ However, in the latter countries, there is very little, if any, opportunistic CRC screening using colonoscopy, whereas Ontario's programme operates in a hybrid environment where opportunistic colonoscopy is available as the initial screening test in persons at average risk. It has been noted that uptake of FOBT may be lower in settings such as Ontario or Australia, ${ }^{43}$ where opportunistic screening is available. ${ }^{44}$ The findings from the current study indicate that physician-linked invitations for CRC screening can be effective in increasing uptake of FOBT in programmes that operate in the context of opportunistic colonoscopy for average risk screening.

Our study has several limitations. First, we are unable to determine family history using Ontario administrative data. A second limitation is that a single generic letter was used. Tailored letters with key messages for specific subgroups may be more effective ${ }^{16}$-an approach that may be relevant in Ontario as we did find that response to the letter appeared to differ in various subgroups. Additionally, while our findings are promising, there are challenges to adoption by other population-based screening programmes, including the need for a centralised database that links patients to their physicians. Finally, implementation of this strategy in populationbased screening is predicated on physician acceptability and agreement. While we have found that this approach is acceptable in principle to many Ontario physicians, ${ }^{45}$ processes to confirm individual physician agreement have not been determined for the entire CCC programme which comprises an estimated 7000 primary care physicians.

\section{CONCLUSIONS}

In summary, we have demonstrated that physician-linked mailed invitations for CRC screening, even without the inclusion of an FOBT kit, can have a substantial effect on participation in an organised CRC screening programme and that it is technically feasible to centrally organise and mail physician-linked invitations on a large scale. Organised screening programmes, which often use unlinked invitations, should consider adopting this approach given its demonstrated effectiveness and feasibility.

\section{Author affiliations}

${ }^{1}$ Department of Medicine, Sunnybrook Health Sciences Centre, Toronto, Ontario, Canada

${ }^{2}$ Institute for Clinical Evaluative Sciences, Toronto, Ontario, Canada

${ }^{3}$ Institute of Health Policy Management and Evaluation, University of Toronto, Toronto, Ontario, Canada

${ }^{4}$ Cancer Care Ontario, Toronto, Ontario, Canada

${ }^{5}$ Department of General Surgery and Li Ka Shing Knowledge Institute,

St. Michael's Hospital, Toronto, Ontario, Canada

${ }^{6}$ Department of Radiation Oncology, Sunnybrook Health Sciences Centre,

Toronto, Ontario, Canada

${ }^{7}$ Dalla Lana School of Public Health, University of Toronto, Toronto, Ontario, Canada 
Acknowledgements The authors would like to acknowledge Peter Austin, $\mathrm{PhD}$ for his expert statistic advice. They also wish to acknowledge the support of the Institutes for Clinical Evaluative Sciences, the Ontario Ministry of Health and Long Term Care and Cancer Care Ontario (CCO).

Contributors The authors contributed substantially to each of the following areas: JT, LFP and LR participated in conception and design. JT, NNB, LFP, $\mathrm{LR}, \mathrm{RS}$ and $\mathrm{LY}$ participated in analysis and interpretation of data. JT participated in drafting the article. All authors participated in revising the article critically for important intellectual content and final approval of the version to be published.

Funding This study was conducted with funding support from the Ontario Institute for Cancer Research and CCO's Health Services Research Network, which is independent of the ColonCancerCheck programme. This work was also supported in part by a grant from the Canadian Institutes for Health Research (grant \# CST-85478).

Competing interests JT was supported by a Canadian Institutes of Health Research New Investigator Award during the period of this study and was the lead scientist for the ColonCancerCheck programme and LR oversees the ColonCancerCheck programme in her capacity as the Vice-President, Cancer Prevention and Control at CCO.

Ethics approval Ethics approval was obtained from the research ethics boards at Sunnybrook Health Sciences Centre and the Institute for Clinical Evaluative Sciences (ICES) and permission to use the Pilot data was obtained from CCO's Data Access Committee.

Provenance and peer review Not commissioned; externally peer reviewed.

Data sharing statement Under Ontario's privacy legislation, neither CCO nor the ICES is permitted to share individual level data from the submitted work.

Open Access This is an Open Access article distributed in accordance with the Creative Commons Attribution Non Commercial (CC BY-NC 3.0) license, which permits others to distribute, remix, adapt, build upon this work noncommercially, and license their derivative works on different terms, provided the original work is properly cited and the use is non-commercial. See: http:// creativecommons.org/licenses/by-nc/3.0/

\section{REFERENCES}

1. Canadian Cancer Society's Steering Committee on Cancer Statistics. Canadian cancer statistics 2013. Toronto, ON: Canadian Cancer Society, 2013.

2. Mandel JS, Church TR, Bond JH, et al. The effect of fecal occult-blood screening on the incidence of colorectal cancer. $N$ Eng J Med 2000;343:1603-7.

3. Hardcastle JD, Chamberlain JO, Robinson $\mathrm{MH}$, et al. Randomised controlled trial of faecal-occult-blood screening for colorectal cancer. Lancet 1996;348:1472-7.

4. Kronborg O, Fenger $\mathrm{C}$, Olsen $\mathrm{J}$, et al. Randomised study of screening for colorectal cancer with faecal-occult-blood test. Lancet 1996;348:1467-71.

5. Atkin WS, Edwards R, Kralj-Hans I, et al. Once-only flexible sigmoidoscopy screening in prevention of colorectal cancer: a multicentre randomised controlled trial. Lancet 2010;375:1624-33.

6. Segnan N, Armaroli P, Bonelli L, et al. Once-only sigmoidoscopy in colorectal cancer screening: follow-up findings of the Italian randomized controlled trial-SCORE. J Natl Cancer Inst 2011;103:1310-22.

7. Schoen RE, Pinsky PF, Weissfeld JL, et al. Colorectal-cancer incidence and mortality with screening flexible sigmoidoscopy. N Engl J Med 2012;366:2345-57.

8. Miles A, Cockburn J, Smith RA, et al. A perspective from countries using organized screening programs. Cancer 2004;104(Suppl 5):1201-13

9. International Cancer Screening Network. Inventory of colorectal cancer screening activities in ICSN countries, May 2008. Secondary inventory of colorectal cancer screening activities in ICSN countries, May 2008. Feb 9 2009. http://appliedresearch.cancer.gov/icsn/ colorectal/screening.html

10. Anonymous. Colon cancer check: Ontario's colorectal cancer screening program. Secondary colon cancer check: Ontario's colorectal cancer screening program Feb 2, 2012. http://health.gov. on.ca/en/public/programs/coloncancercheck/
11. Pignone M, Campbell MK, Carr C, et al. Meta-analysis of dietary restriction during fecal occult blood testing. Eff Clin Pract 2001;4:150-6.

12. Glazier $\mathrm{RH}$, Zagorski BM, Rayner J. Comparison of primary care models in Ontario by demographics, case mix and emergency department use, 2008/09 to 2009/10. ICES investigative report. Toronto: Institute for Clinical Evaluative Sciences, 2012

13. HealthForceOntario. Family practice models. Secondary family practice models May 3 2013. http://www.healthforceontario.ca/Work OutsideOntario/PhysiciansOutsideOntario/PractisingInOntario/ family_practice_models.aspx

14. Ontario Ministry of Health and Long-Term Care. Bulletin 4482: ColonCancerCheck Physician Incentives. Secondary Bulletin 4482: ColonCancerCheck Physician Incentives. July 22, 2008. http://www. health.gov.on.ca/en/pro/programs/ohip/bulletins/4000/bul4482.pdf

15. Khalid-de Bakker C, Jonkers D, Smits K, et al. Participation in colorectal cancer screening trials after first-time invitation: a systematic review. Endoscopy 2011;43:1059-86.

16. Rawl SM, Skinner CS, Perkins SM, et al. Computer-delivered tailored intervention improves colon cancer screening knowledge and health beliefs of African-Americans. Health Educ Res 2012;27:868-85.

17. Alharbi $O$, Rabeneck $L$, Sutradhar $R$, et al. A population-based analysis of outpatient colonoscopy in adults assisted by an anesthesiologist. Anesthesiology 2009;111:734-40.

18. Robles SC, Marrett LD, Clarke EA et al. An application of capture-recapture methods to the estimation of completeness of cancer registration. J Clin Epidemiol 1988;41:495-501.

19. Alter DA, Naylor CD, Austin P, et al. Effects of socioeconomic status on access to invasive cardiac procedures and on mortality after acute myocardial infarction. N Engl J Med 1999;341:1359-67.

20. Singh SM, Paszat LF, Li C, et al. Association of socioeconomic status and receipt of colorectal cancer investigations: a population-based retrospective cohort study. CMAJ 2004;171:461-5.

21. Anonymous. Ontario's Local Health Integration Networks. Secondary Ontario's Local Health Integration Networks May 30 2013. http://www.Ihins.on.ca/home.aspx

22. Anonymous. The Johns Hopkins University ACG Case-Mix System. Secondary The Johns Hopkins University ACG Case-Mix System 2012. http://www.acg.jhsph.edu/

23. Austin PC, van Walraven C, Wodchis WP, et al. Using the Johns Hopkins Aggregated Diagnosis Groups (ADGs) to predict mortality in a general adult population cohort in Ontario, Canada. Med Care 2011;49:932-9.

24. Ray JG, Vermeulen MJ, Schull MJ, et al. Results of the Recent Immigrant Pregnancy and Perinatal Long-term Evaluation Study (RIPPLES). CMAJ 2007;176:1419-26.

25. Glazier RH, Klein-Geltink J, Kopp A, et al. Capitation and enhanced fee-for-service models for primary care reform: a population-based evaluation. CMAJ 2009;180:E72-81.

26. Dahrouge S, Hogg WE, Russell G, et al. Impact of remuneration and organizational factors on completing preventive manoeuvres in primary care practices. CMAJ 2012;184:E135-43.

27. Liang K, Zeger SL. Longitudinal data analysis using generalized linear models. Biometrika 1986;73:13-22.

28. D'Agostino RB Jr. Propensity score methods for bias reduction in the comparison of a treatment to a non-randomized control group. Stat Med 1998;17:2265-81.

29. Austin PC. An introduction to propensity score methods for reducing the effects of confounding in observational studies. Multivariate Behav Res 2011;46:399-424.

30. Normand ST, Landrum MB, Guadagnoli E, et al. Validating recommendations for coronary angiography following acute myocardial infarction in the elderly: a matched analysis using propensity scores. J Clin Epidemiol 2001;54:387-98.

31. Cole SR, Young GP, Byrne D, et al. Participation in screening for colorectal cancer based on a faecal occult blood test is improved by endorsement by the primary care practitioner. $J$ Med Screen 2002:9:147-52.

32. Zajac IT, Whibley AH, Cole SR, et al. Endorsement by the primary care practitioner consistently improves participation in screening for colorectal cancer: a longitudinal analysis. J Med Screen 2010;17:19-24.

33. Grazzini $\mathrm{G}$, Castiglione $\mathrm{G}$, Isu A, et al. Colorectal cancer screening by fecal occult blood testing: results of a population-based experience. Tumori 2000;86:384-8.

34. Myers RE, Sifri R, Hyslop $\mathrm{T}$, et al. A randomized controlled trial of the impact of targeted and tailored interventions on colorectal cancer screening. Cancer 2007;110:2083-91.

35. Sequist TD, Zaslavsky AM, Marshall R, et al. Patient and physician reminders to promote colorectal cancer screening: a randomized controlled trial. Arch Intern Med 2009;169:364-71. 
36. Walsh JM, Salazar R, Terdiman JP, et al. Promoting use of colorectal cancer screening tests. Can we change physician behavior? J Gen Intern Med 2005;20:1097-101.

37. Hewitson $\mathrm{P}$, Ward AM, Heneghan $\mathrm{C}$, et al. Primary care endorsement letter and a patient leaflet to improve participation in colorectal cancer screening: results of a factorial randomised trial. $\mathrm{Br}$ $J$ Cancer 2011;105:475-80.

38. Giorgi Rossi P, Grazzini G, Anti M, et al. Direct mailing of faecal occult blood tests for colorectal cancer screening: a randomized population study from Central Italy. J Med Screen 2011;18:121-7.

39. Cancer Quality Council of Ontario. Colorectal Cancer Screening: Participation. Secondary Colorectal Cancer Screening: Participation. 2013. http://www.csqi.on.ca/cms/one.aspx?portalld=258922\& pageld=273238-.UijqNMakrmQ

40. Logan RF, Patnick J, Nickerson C, et al. Outcomes of the Bowe Cancer Screening Programme (BCSP) in England after the first 1 million tests. Gut 2012;61:1439-46.

41. Parente F, Boemo C, Ardizzoia A, et al. Outcomes and cost evaluation of the first two rounds of a colorectal cancer screening program based on immunochemical fecal occult blood test in northern Italy. Endoscopy 2013;45:27-34.

42. New Zealand Ministry of Health. Bowel Screening Pilot January to June 2012 results. Secondary Bowel Screening Pilot January to June 2012 results 26 April 2013. http://www.health.govt.nz/our-work/ diseases-and-conditions/cancer-programme/bowel-cancerprogramme/bowel-screening-pilot/bowel-screening-pilot-results/ bowel-screening-pilot-january-june-2012-results

43. Zajac IT, Flight I, Turnbull D, et al. Self-reported bowel screening rates in older Australians and the implications for public health screening programs. Australas Med J 2013;6:411-17.

44. Moss SM, Ancelle-Park R, Brenner $\mathrm{H}$. Evaluation and interpretation of screening outcomes. In: Patnick J, Segnan N, von Karsa L, eds. European guidelines for quality assurance in colorectal cancer screening and diagnosis. Luxembrourg: International Agency for Research on Cancer, 2010:71-102.

45. Tinmouth J, Ritvo P, McGregor SE, et al. ColonCancerCheck Primary Care Invitation Pilot project: family physician perceptions. Can Fam Physician 2012;58:e570-7. 